\title{
Prehypertension, Hypertension and Associated Cardiovascular Risk Factors among Adult Congolese Urban Dwellers: Results of the Vitaraa Study
}

\author{
Mwasa Pascal Bayauli'1,2, Jean-René M'Buyamba-Kayamba', Daniel Lemogoum³, \\ Robert Fagard4, Jean Paul Degaute3, Mpandamadi Symphorien Ditu², \\ Bompeka François Lepira ${ }^{5}$, Jean-René M'Buyamba-Kabangu ${ }^{{ }^{*}}$ \\ ${ }^{1}$ Hypertension Unit/Cardiology, Department of Internal Medicine, University of Kinshasa Hospital, Kinshasa, \\ The Democratic Republic of the Congo \\ ${ }^{2}$ Division of Endocrinology and Nuclear Medicine, Department of Internal Medicine, University of Kinshasa \\ Hospital, Kinshasa, The Democratic Republic of the Congo \\ ${ }^{3}$ Erasmus Hospital, Brussels Free University, Brussels, Belgium \\ ${ }^{4}$ Division of Hypertension and Cardiovascular Rehabilitation, University of Leuven, Leuven, Belgium \\ ${ }^{5}$ Division of Nephrology, Department of Internal Medicine, University of Kinshasa Hospital, Kinshasa, \\ The Democratic Republic of the Congo \\ Email: ${ }^{*}$ jerembu@yahoo.fr
}

Received 16 May 2014; revised 27 June 2014; accepted 10 July 2014

Copyright (C) 2014 by authors and Scientific Research Publishing Inc.

This work is licensed under the Creative Commons Attribution International License (CC BY).

http://creativecommons.org/licenses/by/4.0/

c) (i) Open Access

\section{Abstract}

Objective: To assess the prevalence of prehypertension and hypertension, their determinants and associated cardiovascular risk factors in Congolese urban dwellers. Methods: From July 2007 to March 2008, we collected information on lifestyle habits, medical history and anthropometric data in 1292 household members of Adoula Quarter, Kinshasa, aged 20 years or more, 731 women (56.6\%). We obtained measurements of BP, blood glucose, serum lipids and qualitative proteinuria. We defined blood pressure categories according to JNC7 classification and used logistic regression analyses to assess their independent determinants. We obtained age adjustment of continuous and categorical variables using GLM and Genmod procedures, respectively. Results: Prehypertension was observed in $30.3 \%$ of subjects, $34.9 \%$ of men and $26.7 \%$ of women $(P=$ 0.0045 ). The prevalence of hypertension amounted to $30.9 \%$ with no difference between genders. Participants with prehypertension had average age, BMI and waist circumference intermediate between those with normal BP and hypertensive subjects. Their glucose and lipids levels were

"Corresponding author.

How to cite this paper: Bayauli, M.P., et al. (2014) Prehypertension, Hypertension and Associated Cardiovascular Risk Factors among Adult Congolese Urban Dwellers: Results of the Vitaraa Study. World Journal of Cardiovascular Diseases, 4, 390-398. http://dx.doi.org/10.4236/wjcd.2014.48049 
similar to those of normotensives. The prevalence of prehypertension amounted to $33 \%$ at age 20 - 29 years and decreased to $16.7 \%$ at $\geq 60$ years whereas the prevalence of hypertension increased from $11.2 \%$ to $\mathbf{7 1 . 4 \%}$. The rates of diabetes mellitus were similar accross blood pressure catogories whilst prevalences of overweight/obesity, abdominal adiposity, dyslipidemia and metabolic syndrome significatively increased $(P=0.05$ or less). Among participants with prehypertension, $73 \%$ had two or more additional cardiovascular risk factors. In the logistic model the probability of prehypertension was higher in men (OR: 1.429; 95\% CI: 1.099 - 1.857) and participants with overweight/obesity (OR: 1.666; $1.146-2.422)$, lower in participants aged $\geq 55$ years $(0.427 ; 0.267$ - 0.683) and those with high fruit intake $(0.691 ; 0.488-0.977)$. The probability of hypertension was higher in participants aged $\geq 55$ years (OR: 6.988; $4.561-10.706)$, overweight/obesity $(2.263$; 1.704 - 3.004), those with high vegetables consumption $(1.152 ; 1.003-1.324)$ and faster pulse rate (1.013; 1.002 - 1.025). Conclusion: Our results suggest that fruit consumption and control of overweight are important issues for prevention of cardiovascular disease in sub-Saharan Africa where high blood pressure is the main driver of the current epidemic.

\section{Keywords}

Prehypertension, Hypertension, Cardiovascular Risk Factors, Africans

\section{Introduction}

In sub-Saharan Africa, chronic non communicable diseases are expected to account for $46 \%$ of all deaths by 2030 according to World Health Organisation prevision [1]. With between $20 \%$ and 50\% of adult people affected in western societies and $25 \%$ to $28 \%$ in the Africans, hypertension is among the most prevalent chronic non communicable conditions [2]. Elevation of systolic blood pressure by $20 \mathrm{~mm} \mathrm{Hg}$ or diastolic blood pressure by $10 \mathrm{mmHg}$ above the threshold of 115/75 mmHg was reported to twofold increase cardiovascular mortality [3]. Such an elevation conveys arterial blood pressure in JNC7 category of pre-hypertension defined as systolic blood pressure of 120 - $139 \mathrm{mmHg}$ and/or diastolic blood pressure of 80 - $89 \mathrm{mmHg}$ [4]. Pre-hypertension appears to be an intermediate step towards definite hypertension. It is 1.65 times more likely to be associated with another risk factor thereby considerably raising the odds of severe cardiovascular events. Therefore, non pharmacological treatment of the subjects with prehypertension is highly advised with the potential to avoid the development of high blood pressure and the various subsequent clinical disorders [5]-[9].

In the Democratic Republic of the Congo (DRC) the elevated prevalence of hypertension among urban dwellers [10] [11] was reported to be associated with gloomy complications such as strokes, cardiac failure and chronic kidney disease the management of which is limited by scarce resources and poverty [12]. To curb hypertension induced morbidity and mortality, it appears mandatory to identify, control and prevent determinants of blood pressure elevation in the community. Therefore, in the present study we assessed the magnitude of prehypertension and hypertension, their determinants and associated cardiovascular risk factors among adult inhabitants of a Congolese urban community in the framework of the VITARAA Study (VIsite de la Tension Artérielle et du Risque Associé en Afrique).

\section{Methods}

The population of Adoula Quarter of Kinshasa (the Democratic Republic of the Congo) consisted of 27,860 inhabitants living in 3486 households (nearly 8 members/household) with females representing $53.2 \%$ ( $\mathrm{n}=$ $14,820)$. People aged 10 years and over $(n=17,830)$ represented $64 \%$ of the whole population. To identify a $10 \%$ representative sample of the latter people, we randomly selected 350 households expecting a total of 1790 subjects to constitute the target population to be visited at home in the framework of the present survey. At the end of the home visits, 1914 subjects (107\% of the expected total) were approached. Twenty six subjects refused to participate in the study; 1888 individuals were examined. The participation rate was thus $98.6 \%$. However, the files of 64 participants got lost during the transfer from the quarter to our office, leaving data of 1824 subjects available for analysis. Because age (average: $35 \pm 17$ years) and gender distribution (49 females; 54.4\%) of 
these 90 subjects not included in the study were similar to those of the whole study group, we felt the incidents would not seriously impact the study outcomes. From July 2007 to March 2008, two working days per week, teams of properly trained health professionals visited the households between 6.00 and $9.00 \mathrm{pm}$.

The present analysis focuses on adult subjects aged 20 years or more $(n=1292 ; 731$ women: 56.6\%) from whom we obtained demographic data, history of hypertension and diabetes mellitus and current medication for chronic diseases. We collected information on their leisure time physical activity, use of alcohol and tobacco, and weekly consumption of vegetables and fruits. We measured their body weight, height, waist circumference, sitting blood pressure and heart rate, casual blood glucose and plasma lipids concentrations.

Using a validated electronic device (OMRON M6, HEM 7001E) with appropriate cuff fitted to the upper right arm circumference, two consecutive measurements of blood pressure were recorded after the subject had relaxed five minutes or more in the sitting position. A third measurement was obtained if the first two differed by at least $10 \mathrm{mmHg}$. The brachial pulse rate was recorded together with blood pressure. For analysis, we averaged these blood pressure and pulse rate readings. The calibration of blood pressure monitors was checked every four weeks against a standard mercury sphygmomanometer using a T-tube and applying static pressures ranging from 0 to $200 \mathrm{mmHg}$ at $50 \mathrm{mmHg}$ intervals. Devices that deviated by $4 \mathrm{mmHg}$ or more were replaced by new machines. With the subject in loose clothing without shoes, we obtained a body weight measurement to the nearest 100 grams using an electronic scale (Terraillon; TT100, Terraillon SAV MGF Logistique, Gennevilliers, France), and, to the nearest centimeter, a body height and a waist circumference using a tape measurer. Body mass index was weight in kilograms divided by the square of height in meters. We applied a dipstick test (Medi Test Combi 9, Düren, Germany) on freshly voided urine samples. Proteinuria was a score of + or higher. A random glycaemia was determined on a capillary blood drop (Accu-Chek Aviva, Roche, Mannheim, Germany). A five millilitre blood sample withdrawn from an antecubital vein was centrifuged during five minutes at 3000 rounds/min. The Buffy coat was immediately discarded. The plasma was stored at -70 degrees until determination of lipid concentrations at the laboratory of biochemistry, Erasme Hospital, Brussels, Belgium.

We assessed cardiovascular risk factors according to the 2007 ESH/ESC guidelines [13]. We applied JNC7 categories of blood pressure to define pre-hypertension (systolic blood pressure 120 - $139 \mathrm{mmHg}$ and/or diastolic pressure of 80 - $89 \mathrm{mmHg}$ in subjects exempt of antihypertensive treatment) and hypertension (blood pressure of at least $140 \mathrm{mmHg}$ systolic or $90 \mathrm{mmHg}$ diastolic, or use of antihypertensive drugs) [4]. Overweight/ obesity was a body mass index $\geq 25 \mathrm{~kg} / \mathrm{m}^{2}$ [14]. Abdominal adiposity was a waist circumference of at least 80 $\mathrm{cm}$ or $94 \mathrm{~cm}$ in women and men, respectively [15]. Known diabetes mellitus was a self-reported diagnosis or use of diabetic medication [16]. Hypercholesterolemia was a total cholesterol $>190 \mathrm{mg} / \mathrm{dL}$ or use of lipid lowering medication. Dyslipidemia encompassed triglycerides $>150 \mathrm{mg} / \mathrm{dL}$, LDL-cholesterol $\geq 100 \mathrm{mg} / \mathrm{dL}$, HDL-cholesterol below $50 \mathrm{mg} / \mathrm{dL}$ or $40 \mathrm{mg} / \mathrm{dL}$ in women or men, or the presence of hypercholesterolemia. Metabolic syndrome was defined by coexistent of abdominal adiposity with at least two of the following features [15]: known diabetes mellitus; blood pressure $>130 / 85 \mathrm{mmHg}$ or hypertension; triglycerides $>150 \mathrm{mg} / \mathrm{dL}$ or use of lipid lowering treatment; HDL $<50 \mathrm{mg} / \mathrm{dL}$ in women or $<40 \mathrm{mg} / \mathrm{dL}$ in men. People whose physical activity was less than 30 minutes for at least three days per week were categorized as not engaging in sport. Smokers and alcohol drinkers were participants reporting regular use of tobacco or alcoholic beverages at least once per week. Consumption of at least one vegetable serving five days or one fruit three days per week was considered as high.

\section{Statistical Methods}

For database management and statistical analysis, we used SAS software system, version 9.3 for windows (SAS Institute, Cary, NC). Because of significant differences in age distribution between blood pressure categories continuous variables were expressed as age-adjusted means and their $95 \%$ confidence intervals using analysis of covariance in GLM procedure and categorical variables as age-adjusted prevalences and their $95 \%$ confidence intervals using logistic regression analysis by Genmod procedure. In multivariable' adjusted analyses, we modelled the odds for prehypertension and hypertension using stepwise logistic regression with the P-value for independent variables to enter and stay in the model set at 0.10 . The independent co-variables considered for entry into the model were sex, age, pulse rate, and classification variables $(0.1)$ coding for current smoking, overweight/obesity, abdominal adiposity, physical inactivity, vegetable and fruit consumption, dyslipidemia, proteinuria, and diabetes mellitus. The odds for prehypertension were obtained with hypertensive subjects excluded from the analysis. Statistical significance was a P-value of 0.05 or less on two-sided tests. 


\section{Results}

Characteristics of participants by blood pressure category.

Blood pressure was normal in 502 participants (39.8\%), whilst 391 (30.3\%) and 399 subjects (30.9\%) had prehypertension and definite hypertension, respectively. The participants' age averaged $37 \pm 15$ years for the whole study population with significant differences $(\mathrm{F}=161.23$; $\mathrm{P}<0.0001)$ observed between categories of normal blood pressure (31 \pm 12 years), prehypertension ( $35 \pm 13$ years) and hypertension (47 \pm 16 years). Table 1 shows age-adjusted means and 95\% confidence intervals of clinical and biological characteristics and age-adjusted prevalences of additional risk factors in the three categories of blood pressure.

Prehypertension predominated among men $(34.9 \%$ vs $26.7 \%$; $\mathrm{P}=0.0045)$ whereas definite hypertension tended to affect more women than men $(31.7 \%$ vs $29.8 \%$; $\mathrm{P}=0.0748)$. Subjects with prehypertension had average body mass index and waist circumference intermediate between those of individuals with normal blood pressure and definite hypertension. Pulse rate, blood glucose, total cholesterol, LDL cholesterol and triglycerides levels significantly increased with the categories of blood pressure.

For the whole study population overweight/obesity, abdominal adiposity and dyslipidemia were observed, respectively in 545 (42.2\%), 553 (42.8\%) and 636 (81\%) participants. Respectively 68 (5.3\%), 490 (37.9\%), 722 (55.9\%) and 469 (36.3\%) participants reported tobacco use, alcohol intake, low fruits and vegetables consumption. Known diabetes mellitus and metabolic syndrome were found in 54 (4.2\%) and 96 (7.4\%) subjects, respectively. The rate of overweight/obesity, central adiposity, dyslipidemia and metabolic syndrome significantly increased with category of blood pressure ( $\mathrm{P}<0.05$ or less). The proportion of additional risk factors was similar in the group of normal blood pressure and prehypertension.

Table 1. Clinical and biological characteristics of participants in various blood pressure categories.

\begin{tabular}{|c|c|c|c|c|}
\hline Characteristic & Normal BP & Prehypertension & Hypertension & \\
\hline $\mathrm{n}(\%)$ & $502(38.8 \%)$ & $391(30.3 \%)$ & $399(30.9 \%)$ & \\
\hline \multicolumn{4}{|c|}{ Age-adjusted means ( $95 \%$ confidence intervals) of characteristic } & $\mathrm{P}$ \\
\hline BMI, $\mathrm{kg} / \mathrm{m}^{2}$ & $24(23.5-24.5)$ & $25(24.5-25.5) \$ £$ & $26.8(26.2-27.3) \$$ & $<0.0001$ \\
\hline Waist, cm & $81.4(80.3-82.5)$ & $84.5(83.3-85.8) \$ £$ & $89.5(88.2-90.7) \$$ & $<0.0001$ \\
\hline Heart rate, beats/min & $78(76-79)$ & $77(76-78) £$ & $80(78-81)$ & 0.0021 \\
\hline Plasma glucose, mg/dl & $107(102-113)$ & $106(101-111)$ & $113(108-119)$ & $<0.0001$ \\
\hline $\mathrm{TC}, \mathrm{mg} / \mathrm{dl}$ & $170(165-175)$ & $172(167-177)$ & $174(168-179)$ & $<0.0001$ \\
\hline HDL-C, mg/dl & $44(43-46)$ & $43(42-45)$ & $44(42-46)$ & 0.2603 \\
\hline LDL-C, mg/dl & $102(98-106)$ & $105 \quad(100-109)$ & $104(99-108)$ & $<0.0001$ \\
\hline Triglycerides, mg/dl & $120(110-131)$ & $124(113-135)$ & $135(124-147)$ & $<0.0001$ \\
\hline \multicolumn{4}{|c|}{ Age-adjusted prevalence (\%) and (95\% confidence intervals) of characteristic } & $\mathrm{P}$ \\
\hline Overweight/obesity & $35.1(30.9-39.3)$ & $41.6(37-46.2) £$ & $52.2(47.3-57.1)$ & $<0.0001$ \\
\hline Abdominal obesity & $22.5(18.6-26.4)$ & $25.9(21.6-30.1) £$ & $39.6(35-44.1)$ & 0.0013 \\
\hline Low fruit consumption & $57.1(52.6-61.6)$ & $58.0(53.1-63.0)$ & $52.0(47.0-57.5)$ & $<0.0001$ \\
\hline Low legumes intake & $36.5(32.1$ - 40.9) & $39.1(34.3$ - 43.9) & $33.3(28.2-38.4)$ & $<0.0001$ \\
\hline Tobacco use & $5.6(3.5-7.7)$ & $5.1(2.8-7.4)$ & $5.7(3.2-8.1)$ & 0.0006 \\
\hline Diabetes & $3.4(1.6-5.2)$ & $3.6(1.7-5.6)$ & $5.7(3.6-7.8)$ & 0.7575 \\
\hline Dyslipidemia & $69.8(64.6-75.1)$ & $71.4(65.9$ - 77) & 78.8 (72.9 - 84.6) & $<0.0001$ \\
\hline Metabolic syndrome & $1.6(-1.8-5.1)$ & $2.4(-1.2-6.1)$ & $41(37.2-45)$ & $<0.0001$ \\
\hline
\end{tabular}

Values are age-adjusted means or prevalences and 95\% confidence intervals. The lipids measurements were obtained in 786 subjects (428 women and 358 men): 292 with normal BP, 245 with prehypertension and 249 with hypertension. TC = Total cholesterol, HDL-C = HDL cholesterol, LDL-C = LDL Cholesterol, \$ = significant difference in comparison to normal blood pressure; $£=$ significant difference in comparison to hypertensive subjects. 
In participants aged 20 - 29 years the prevalence of prehypertension amounted to 33\% for both genders combined and was only $16.7 \%$ in those above 60 years whereas the prevalence of hypertension significantly increased from $11.2 \%$ to $71.4 \%$.

In the logistic model (Table 2), the probability to present prehypertension was greater for male gender (odd ratio: 1.429; [95\% confidence interval 1.099 - 1.857]; $\mathrm{P}=0.0077)$ and overweight/obese subjects (1.666 [1.146 2.422]; $\mathrm{P}=0.0075)$; it was lower for participants $\geq 55$ years $(0.427$ [0.267 - 0.683]; $\mathrm{P}=0.0004)$ and those with higher fruit consumption (0.691 [0.488 - 0.977]; $\mathrm{P}=0.0362)$. The probability of hypertension was higher in participants aged $\geq 55$ years (6.988 [4.561 - 10.706]; P < 0.0001), with overweight/obesity (2.263 [1.704 - 3.004]; P $<0.0001)$, higher legumes consumption (1.152 [1.003 - 1.324]; $\mathrm{P}=0.0453)$ and faster pulse rate (1.013 [1.002 1.025]; $\mathrm{P}=0.0249$ ).

\section{Discussion}

The main finding of the present study was the elevated prevalence of prehypertension and hypertension in this Congolese urban population. The prevalence of prehypertension was higher among males than that among females and in overweight/obese subjects; it was lower in those above age 55 years and in participants with high weekly fruit consumption. The elevated prevalence of hypertension in this urban population was accounted for by aging, overweight/obesity, faster pulse rate and, paradoxically, by increased vegetables consumption.

The observed prevalence of prehypertension is of the same magnitude (31\%) as reported in United States [17] but somewhat lower than that found in Beijing (35.7\%) [18] or among the Ashanti of Ghana (40\%) [19]. Likewise, the rate of $14.5 \%$ in the Turkish region of Trabzon [20] was also lower than that in the present work. Despite this discrepancy, our data concur with most studies [17]-[21] with regard to the predominance of male gender among people with prehypertension. Indeed, in the logistic model the risk of prehypertension was 1.4 times greater in men than that in women. The rate of prehypertension was high below age 30 and tended to decline thereafter whilst for both genders combined the prevalence of definite hypertension increased. Such an observation confirms the transient nature of prehypertension and its tendency to progress towards definite hypertension with aging. Over the age of 55 years, the logistic model suggests the prevalence of prehypertension was about $57 \%$ lower than that at younger age.

Prehypertension was rarely an isolated condition. Most participants with prehypertension displayed at least two additional cardiovascular risk factors and had indices of obesity that were intermediate between subjects with normal blood pressure and those with definite hypertension. The association of prehypertension or hypertension and overweight/obesity concurs with the literature [20]-[26] and is known to major the risk of atherosclerosis [27] [28]. Overweight/obesity is characterized by sympathetic overload responsible for elevated systemic vascular resistance [29] [30] and expanded extracellular volume through which cardiac output and blood pressure can be increased [31] [32].

Our work highlights the low risk of prehypertension among participants with high fruit consumption. Poor dietary vegetables and fruits intake and sedentary life favour development of insulin resistance, type 2 diabetes mellitus, metabolic syndrome and cardiovascular diseases [33]-[35]. High fruit consumption might result in increased potassium intake the beneficial effect of which on blood pressure level had already been demonstrated [36]. Potassium is known to induce natriuresis and vasodilatation responsible for reduction in extracellular vol-

Table 2. Independent determinants of prehypertension and hypertension.

\begin{tabular}{|c|c|c|c|c|c|c|}
\hline \multirow{2}{*}{ Determinant } & \multicolumn{3}{|c|}{ Prehypertension } & \multicolumn{3}{|c|}{ Hypertension } \\
\hline & Odd ratio & $95 \% \mathrm{CI}$ & $\mathbf{P}$ & Odd ratio & $95 \% \mathrm{CI}$ & $\mathbf{P}$ \\
\hline Male gender & 1.429 & $1.099-1.857$ & 0.0077 & - & - & \\
\hline Age $\geq 55$ years & 0.427 & $0.267-0.683$ & 0.0004 & 6.988 & $4.561-10.706$ & $<0.0001$ \\
\hline Overweight/obesity & 1.666 & $1.146-2.422$ & 0.0075 & 2.263 & $1.704-3.004$ & $<0.0001$ \\
\hline Heart rate & - & - & & 1.013 & $1.002-1.025$ & 0.0249 \\
\hline Fruits consumption & 0.691 & $0.488-0.977$ & 0.0362 & - & - & \\
\hline Legumes consumption & - & - & - & 1.152 & $1.003-1.324$ & 0.0453 \\
\hline
\end{tabular}


ume and peripheral vascular resistance [36]. Unfortunately, in the present work, neither serum nor dietary potassium was assessed. Moreover, our logistic model did not include the socio-economic characteristics of participants that were not assessed. Thus, one cannot ascertain whether the association between a low prevalence of prehypertension and a high fruits intake reflects a direct relationship or, does instead imply the higher income of individuals who can afford taking a lot of fruits.

The 30.9\% observed prevalence of hypertension is consistent with other data in the urban Africa [2] [37] [38] and USA (29.6\%) [39]. It is higher than that previously observed in the same community some 23 years ago [40] but somewhat lower than the findings in the Turkish region of Trabzon (44\%) [20], in Europe (44.2\%) [39] or in our report from Bukavu in the Eastern Congo (41.4\%) [11]. The odds for hypertension, higher with ageing, over-weight/obesity and faster pulse rate in the logistic model is a rather common finding. Indeed, through an increase in cardiac output, blood pressure rises in middle aged individuals and through high systemic resistance in the aged. An increase in systemic vascular resistance occurring with advance in age attests endothelial dysfunction due to atherosclerotic vascular wall stiffness favored by oxidative stress and various vasoconstriction mediators. Arterial wall stiffness appears to be a major predictor of cardiovascular events [41].

At variance with most literature, the probability to develop hypertension was greater in our participants with higher vegetables consumption. Such an effect paradoxical in appearance of high vegetables intake in our setting seems to be compatible with the culinary traditions. Consumption of rough vegetables is exceptional among our populations. The way vegetables are processed might be considered the culprit responsible for their apparently offending property.

The global cardiovascular risk appears to be elevated among our participants with prehypertension and hypertension in whom the prevalence of metabolic syndrome was high. Prehypertension and hypertension were associated in most cases with at least two additional cardiovascular risk factors thus enhancing the odds to develop cardiovascular events [9] [19] [20] [42] [43]. The risk in subjects with prehypertension has been attributed to endothelial dysfunction, increased level of pro-inflammatory cytokines and gamma glutamyl-transferase, oxidative stress, and structural remodelling of the myocardium in comparison to subjects with blood pressure in the normal range [9] [23] [44]-[47]. Unlike other studies [11] [37] [48] [49] the rates of diabetes mellitus were similar in our three blood pressure categories whereas in accordance with most reports [18] [19] [23] [50]-[53] the prevalence of dyslipidemia increased.

Our results should be interpreted within the limitations of the present work. First, the definition of prehypertension and hypertension relies on the average of only two blood pressure measurements obtained at a single occasion. These measurements may not reflect the usual blood pressure of the participants. Second, the prevalence of diabetes and metabolic syndrome were surely underestimated. Only patients with known diabetes were identified as such. Because the casual capillary glucose level was not obtained in codified conditions, it was thus not used as a criterion for detection of diabetes mellitus. Third, our urban population is a mixture of participants from a variety of tribal origin and cultures that were surely not evenly represented in our sample. It is therefore uncertain whether the results may be safely extrapolated to the entire Congolese population. Moreover, in view of the population low education level, the accuracy of information concerning life habits cannot be totally warranted. Because accurate procedures to assess visceral adiposity such as tomography or absometry were not readily available, we evaluated abdominal adiposity by means of waist circumference. Finally, the overall cardiovascular risk might have been underestimated since cardiac and renal function was not assessed. Nonetheless, our results suggest that prevention of cardiovascular disease in Africa should encompass measures meant to control determinants of blood pressure elevation, the main driver of the current epidemic.

\section{Acknowledgements}

The authors acknowledge the invaluable assistance of the Administrative Authorities of Adoula quarter (Bandalungwa, Kinshasa) in terms of providing demographic statistics and organizing a sensitization campaign of their population that positively impacted on the realization of the present work. We owe gratitude to the visited household members for their warm and enthusiastic participation. We gratefully thank the teams of observers who implemented the field work. The VITARAA study was made possible thanks to material and financial supports by the Service of Cardiology, Erasme Hospital, Brussels Free University, Belgium, and the contribution of the Belgian Hypertension Committee. The storage of plasma samples was provided by the Centre for Blood Transfusion (Bandalungwa, Kinshasa, the Democratic Republic of the Congo), whilst the Laboratory of 
Biochemistry, Erasme Hospital, Brussels Free University, Belgium, performed the lipid concentration analyses.

\section{References}

[1] World Health Organization (2009) Global Burden of Disease. Projections of Mortality and Burden of Disease, 20022030. http://www.who.int/topics/global_burden_of_disease/en/

[2] Kearney, P.M., Whelton, M., Reynolds, K., Whelton, P.K. and He, J. (2004) Worldwide Prevalence of Hypertension: A Systematic Review. Journal of Hypertension, 22, 11-19. http://dx.doi.org/10.1097/00004872-200401000-00003

[3] Lewington, S., Clarke, R., Qizilbash, N., Peto, R. and Collins, R. (2002) Age-Specific Relevance of Usual Blood Pressure to Vascular Mortality: A Meta-Analysis of Individual Data for One Million Adults in 61 Prospective Studies. Lancet, 360, 1903-1913. http://dx.doi.org/10.1016/S0140-6736(02)11911-8

[4] Joint National Committee on the Prevention, Detection, Evaluation, and Treatment of High Blood Pressure (2003) The Seventh Report of the Joint National Committee on the Prevention, Detection, Evaluation, and Treatment of High Blood Pressure: The JNC-7 Report. JAMA, 289, 2560-2572. http://dx.doi.org/10.1001/jama.289.19.2560

[5] Greenland, K.J., Croft, J.B. and Mensah, G.A. (2004) Prevalence of Heart Disease and Stroke Risk Factors in Persons with Prehypertension in the United States, 1999-2000. Archives of Internal Medicine, 164, 2113-2118. http://dx.doi.org/10.1001/archinte.164.19.2113

[6] Ferdinand, K.C. and Pacini, R.S. (2007) New Evidence Confirms Risks Associated with Prehypertension and Benefits of Therapeutic Lifestyle Changes in Management. Journal of the Cardiometabolic Syndrome, 2, 302-304. http://dx.doi.org/10.1111/j.1559-4564.2007.07620.x

[7] Liszka, H.A., Mainous, A.G., King, D.E., Everett, C.J. and Egan, B.M. (2005) Prehypertension and Cardiovascular Morbidity. Annals of Family Medicine, 3, 294-299. http://dx.doi.org/10.1370/afm.312

[8] Vasan, R.S., Larson, M.G., Leip, E.P., Kannel, W.B. and Levy, D. (2001) Assessment of Frequency of Progression to Hypertension in Non-Hypertensive Participants in the Framingham Heart Study: A Cohort Study. Lancet, 358, 16821686. http://dx.doi.org/10.1016/S0140-6736(01)06710-1

[9] Zhang W.W. and Li N.H. (2011) Prévalence, Risk Factors, and Management of Prehypertension. International Journal of Hypertension, 2011, 1-6. http://dx.doi.org/10.4061/2011/605359

[10] Organisation mondiale de la santé (2006) Enquête sur les facteurs de risque des mlaladies non-transmissibles à Kinshasa. Capitale de la République Démocratique du Congo, selon l'approche STEPS de l’OMS, Rapport d'analyse, Kinshasa.

[11] Katchunga, P.B., M’Buyamba-Kayamba, J.R., Masumbuko, B.E., et al. (2011) Hypertension artérielle chez l’adulte congolais du Sud Kivu: Résultats de l’étude Vitaraa. La Presse Médicale, 40, e315-e323. http://dx.doi.org/10.1016/j.lpm.2010.10.036

[12] Mbaraga, N., Longo-Mbenza, B. and Tshiani, K.A. (1984) Place de l’hypertension artérielle aux Cliniques Universitaires de Kinshasa. Cardiologie Tropicale, 10, 85-89.

[13] ESC and ESH Guidelines (2007) 2007 Guidelines for the Management of Arterial Hypertension/The Task Force for the Management of Arterial Hypertension of the European Society of Hypertension (ESH) and the European Society of cardiology (ESC). European Heart Journal, 28, 1462-1536.

[14] WHO (1997) Obesity: Preventing and Managing the Global Epidemic. Report of a WHO Consultation on Obesity. Geneva, 1-276.

[15] Alberti, K.G.M.M., Eckel, R.H., Grundy, S.M., Zimmet, P.Z., Cleeman, J.I., Donato, K.A., Fruchart, J.-C., James, W.P.T., Loria, C.M. and Smith Jr., S.C. (2009) Harmonizing the Metabolic Syndrome: A Joint Interim Statement of the International Diabetes Federation Task Force on Epidemiology and Prevention; National Heart, Lung, and Blood Institute; American Heart Association; World Heart Federation; International Atherosclerosis Society; and International Association for the Study of Obesity. Circulation, 120, 1640-1645. http://dx.doi.org/10.1161/CIRCULATIONAHA.109.192644

[16] American Diabetes Association (2010) Diagnosis and Classification of Diabetes Mellitus. Diabetes Care, 33, S62-S69. http://dx.doi.org/10.2337/dc10-S062

[17] Wang, Y. and Wang, Q.J. (2004) The Prevalence of Prehypertension and Hypertension among US Adults According to the New Joint National Committee Guidelines: New Challenges of the Old Problem. Archives of Internal Medicine, 164, 2126-2134. http://dx.doi.org/10.1001/archinte.164.19.2126

[18] Zhang, W.H., Zhang, L., An, W.F. and Ma, J.L. (2011) Prehypertension and Clustering of Cardiovascular Risk Factors among Adults in Suburban Beijing, China. Journal of Epidemiology, 21, 1-7.

[19] Agyemang, C. and Owusu-Dabo, E. (2008) Prehypertension in the Ashanti Region of Ghana, West Africa: An Opportunity for Early Prevention of Clinical Hypertension. Public Health, 122, 19-24. 
http://dx.doi.org/10.1016/j.puhe.2007.04.015

[20] Erem, C., Hacihasanoglu, A., Kocak, M., Deger, O. and Topbas, M. (2008) Prevalence of Prehypertension and Hypertension and Associated Risk Factors among Turkish Adults: Trabzon Hypertension Study. Journal of Public Health, 31, 47-58. http://dx.doi.org/10.1093/pubmed/fdn078

[21] Ganguly, S.S., Al-Shafaee, M.A., Bhargava, K. and Duttagupta, K.K. (2008) Prevalence of Prehypertension and Associated Cardiovascular Risk Profiles among Prediabetic Omani Adults. BMC Pub Health, 8, 108. http://dx.doi.org/10.1186/1471-2458-8-108

[22] Cordero, A., Laclaustra, M., Leon, M., et al. (2006) Prehypertension Is Associated with Insulin Resistance State and Not with an Initial Renal Function Impairment: A Metabolic Syndrome in Active Subjects in Spain (MESYAS) Registry substudy. American Journal of Hypertension, 19, 189-196. http://dx.doi.org/10.1016/j.amjhyper.2005.08.018

[23] Shanthirani, S.C., Pradeepa, R., Deepa, R., et al. (2003) Prevalence and Risk Factors of Hypertension in a Selected South Indian Population-The Chennai Urbain Population Study. The Journal of the Association of Physicians of India, 51, 20-27.

[24] Stein, A.D., Stoyanovsky, V., Mincheva, V., et al. (2000) Prevalence, Awareness, Treatment and Control of Hypertension in a Working Bulgarian Population. European Journal of Epidemiology, 16, 265-270. http://dx.doi.org/10.1023/A:1007601107752

[25] Kim, B.J., Lee, H.J., Sung, K.C., et al. (2007) Comparison of Microalbuminuria in 2 Blood Pressure Categories of Prehypertensive Subjects. Circulation Journal, 71, 1283-1287. http://dx.doi.org/10.1253/circj.71.1283

[26] Tsujimoto, T., Sairenchi, T., Iso, H., Irie, F., Yamagishi, K., Tanaka, K., Muto, T. and Ota, H. (2012) Impact of Obesity on Incident Hypertension Independent of Weight Gain among Nonhypertensive Japanese: The Ibaraki Prefectural Health Study (IPHS). Journal of Hypertension, 30, 1122-1128. http://dx.doi.org/10.1097/HJH.0b013e328352b879

[27] Jordan, J., Yumuk, V., Schlaich, M., Nilsson, P.M., Zahorska-Markiewicz, B., Grassi, G., Schmieder, R.E., Engeli, S. and Finer, N. (2012) Joint Statement of the European Association for the Study of Obesity and the European Society of Hypertension: Obesity and Difficult to Treat Arterial Hypertension. Journal of Hypertension, 30, 1047-1055. http://dx.doi.org/10.1097/HJH.0b013e3283537347

[28] Egan, B.M., Zhao, Y., Axon, R.N., Brzezinski, W.A. and Ferdinand, K.C. (2011) Uncontrolled and Apparent Treatment Resistant Hypertension in the United States, 1988 to 2008. Circulation, 124, 1046-1058. http://dx.doi.org/10.1161/CIRCULATIONAHA.111.030189

[29] Shibao, C., Gamboa, A., Diedrich, A., Ertl, A.C., Chen, K.Y., Byrne, D.W., Farley, G., Paranjape, S.Y., Davis, S.N. and Biaggioni, I. (2007) Autonomic Contribution to Blood Pressure and Metabolism in Obesity. Hypertension, 49, 27-33. http://dx.doi.org/10.1161/01.HYP.0000251679.87348.05

[30] Wofford, M.R., Anderson, D.C., Brown, C.A., Jones, D.W., Miller, M.E. and Hall, J.E. (2001) Antihypertensive Effect of $\alpha$ - and $\beta$-Adrenergic Blockade in Obese and Lean Hypertensive Subjects. American Journal of Hypertension, 14, 694-698. http://dx.doi.org/10.1016/S0895-7061(01)01293-6

[31] Messerli, F.H., Christie, B., DeCarvalho, J.G., Aristimuno, G.G., Suarez, D.H., Dreslinski, G.R. and Frohlich, E.D. (1981) Obesity and Essential Hypertension. Hemodynamics, Intravascular Volume, Sodium Excretion, and Plasma Renin Activity. JAMA Internal Medicine, 141, 81-85. http://dx.doi.org/10.1001/archinte.1981.00340010073016

[32] Stelfox, H.T., Ahmed, S.B., Ribeiro, R.A., Gettings, E.M., Pomerantsev, E. and Schmidt, U. (2006) Hemodynamic Monitoring in Obese Patients: The Impact of Body Mass Index on Cardiac Output and Stroke Volume. Critical Care Medicine, 34, 1243-1246. http://dx.doi.org/10.1097/01.CCM.0000208358.27005.F4

[33] Mayer-Davis, E.J., D’Agostino, R., Karter, A.J., Haffner, S.M., Rewers, M.J., Saad, M., Bergman, R.N. for the IRAS Investigators (1998) Intensity and Amount of Physical Activity in Relation to Insulin Sensitivity. The Insulin Resistance Atherosclerosis Study. JAMA, 279, 669-674. http://dx.doi.org/10.1001/jama.279.9.669

[34] Riccardi, G. and Rivellese, A.A. (2000) Dietary Treatment of the Metabolic Syndrome, the Optimal Diet. British Journal of Nutrition, 83, S143-S148. http://dx.doi.org/10.1017/S0007114500001082

[35] Hu, F.B., Manson, J.E., Stampfer, M.J., Colditz, G., Liu, S.M., Solomon, C.G. and Willett, W.C. (2001) Diet, Lifestyle and the Risk of Type II Diabetes Mellitus in Women. New England Journal of Medicine, 345, 790-797. http://dx.doi.org/10.1056/NEJMoa010492

[36] Treasure, J. and Ploth, D. (1983) Role of Dietary Potassium in the Treatment of Hypertension. Hypertension, 5, 864872. http://dx.doi.org/10.1161/01.HYP.5.6.864

[37] Baldé, A.M., Traoré, S., Touré, M., Diallo, D., Keita, A., Magassouba, F.B., Donzo, M., et al. (2006) Hypertension artérielle en Guinée: Epidémiologie et place de la phytothérapie dans la prise en charge dans les Zones urbaines et rurales de Fria, Boke, Forecariah (Basse Guinée). Pharmacologie et Médecine Traditionnelle Africaines, 12, 19-43.

[38] Kimbally-Kaky, G., Bolanda, J.D., Gokaba, C.H., et al. (2004) Hypertension artérielle et les autres facteurs de risque cardiovasculaires à Brazzaville. STEP/WHO, Brazzaville. 
[39] Flack, J.M., Nasser, S.A. and O’Connor, S.M. (2008) Ethnicity and Socioeconomic Status in Hypertension. In: Izzo, J.L., Sica, D.A. and Black, H.R., Eds., Hypertension Primer: The Essentials of Blood Pressure: Basic Science, Population Science, and Clinical Management, 4th Edition, Council on High Blood Pressure Research, American Heart Association, Dallas, 276-278.

[40] M’Buyamba-Kabangu, J.R., Fagard, R., Lijnen, P., Staessen, J., Ditu, M.S., Tshiani, K.A. and Amery, A. (1986) Epidemiological Study of Blood Pressure and Hypertension in a Sample of Urban Bantu of Zaire. Journal of Hypertension, 4, 485-492. http://dx.doi.org/10.1097/00004872-198608000-00015

[41] Mitchell, G.F., Parise, H., Benjamin, E.J., Larson, M.G., Keyes, M.J., Vita, J.A., Vasan, R.S. and Levy, D. (2004) Changes in Arterial Stiffness and Wave Reflection with Advancing Age in Healthy Men and Women. The Framingham Heart Study. Hypertension, 43, 1239-1245. http://dx.doi.org/10.1161/01.HYP.0000128420.01881.aa

[42] Grossman, A., Grossman, C., Barenboim, E., Azaria, B., Goldstein, L. and Grossman, E. (2006) Pre-Hypertension as a Predictor of Hypertension in Military Aviators: A Longitudinal Study of 367 Men. Aviation, Space, and Environmental Medicine, 77, 1162-1165.

[43] Grotto, I., Grossman, E., Huerta, M. and Sharabi, Y. (2006) Prevalence of Prehypertension and Associated Cardiovascular Risk Profiles among Young Israeli Adults. Hypertension, 48, 254-259. http://dx.doi.org/10.1161/01.HYP.0000227507.69230.fc

[44] Wu, J., Yan, W.H., Qiu, L., Chen, X.Q., Guo, X.Z., Wu, W., Xia, L.Y., Qin, X.Z., Liu, Y.H., Ding, H.T., Han, S.M., $\mathrm{Xu}$, C.L. and Zhu, G.J. (2011) High Prevalence of Coexisting Prehypertension and Prediabetes among Healthy Adults in Northern and Northeastern China. BMC Public Health, 11, 794. http://dx.doi.org/10.1186/1471-2458-11-794

[45] Gupta, A.K. and Johnson, W.D. (2010) Prediabetes and Prehypertension in Disease Free Obese Adults Correlate with an Exacerbated Systemic Proinflammatory Milieu. Journal of Inflammation, 7, 36. http://dx.doi.org/10.1186/1476-9255-7-36

[46] Chrysohoou, C., Pitsavos, C., Panagiotakos, D.B., Skoumas, J. and Stefanadis, C. (2004) Association between Prehypertension Status and Inflammatory Markers Related to Atherosclerotic Disease: The ATTICA Study. American Journal of Hypertension, 17, 568-573. http://dx.doi.org/10.1016/j.amjhyper.2004.03.675

[47] Ninomiya, T., Kubo, M., Doi, Y., Yonemoto, K., Tanizaki, Y., Tsuruya, K., Sueishi, K., Tsuneyoshi, M., Iida, M. and Kiyohara, Y. (2007) Prehypertension Increases the Risk for Renal Arteriosclerosis in Autopsies: The Hisayama Study. Journal of the American Society of Nephrology, 18, 2135-2142. http://dx.doi.org/10.1681/ASN.2007010067

[48] Sowers, J.R. (2003) Recommendations for Special Populations: Diabetes Mellitus and the Metabolic Syndrome. American Journal of Hypertension, 16, 41S-45S. http://dx.doi.org/10.1016/j.amjhyper.2003.07.009

[49] Tarnow, L., Rossing, P., Nielsen, F.S. and Parving, H.H. (1994) Prevalence of Arterial Hypertension in Diabetic Patients after the JNC-V. Diabetes Care, 17, 1247-1251. http://dx.doi.org/10.2337/diacare.17.11.1247

[50] Assmann, G. and Schulte, H. (1988) The Prospective Cardiovascular Munster (PROCAM) Study: Prevalence of Hyperlipidemia in Persons with Hypertension and/or Diabetes Mellitus and the Relationship to Coronary Heart Disease. American Heart Journal, 116, 1713-1724. http://dx.doi.org/10.1016/0002-8703(88)90220-7

[51] Kshirsagar, A.V., Carpenter, M., Bang, H., Wyatt, S.B. and Colindres, R.E. (2006) Blood Pressure Usually Considered Normal Is Associated with an Elevated Risk of Cardiovascular Disease. American Journal of Medicine, 119, $133-141$. http://dx.doi.org/10.1016/j.amjmed.2005.08.023

[52] Hsia, J., Margolis, K.L., Eaton, C.B., Wenger, N.K., Allison, M., Wu, L.L., LaCroix, A.Z., Black, H.R. for Women’s Health Initiative Investigators (2007) Prehypertension and Cardiovascular Disease Risk in the Women's Health Initiative. Circulation, 115, 855-860. http://dx.doi.org/10.1161/CIRCULATIONAHA.106.656850

[53] Washio, M., Tokunaga, S., Yoshimasu, K., Kodama, H., Liu, Y., Sasazuki, S., et al. (2004) Role of Prehypertension in the Development of Coronary Atherosclerosis in Japan. Journal of Epidemiology, 14, 57-62. http://dx.doi.org/10.2188/jea.14.57 
Scientific Research Publishing (SCIRP) is one of the largest Open Access journal publishers. It is currently publishing more than 200 open access, online, peer-reviewed journals covering a wide range of academic disciplines. SCIRP serves the worldwide academic communities and contributes to the progress and application of science with its publication.

Other selected journals from SCIRP are listed as below. Submit your manuscript to us via either submit@scirp.org or Online Submission Portal.
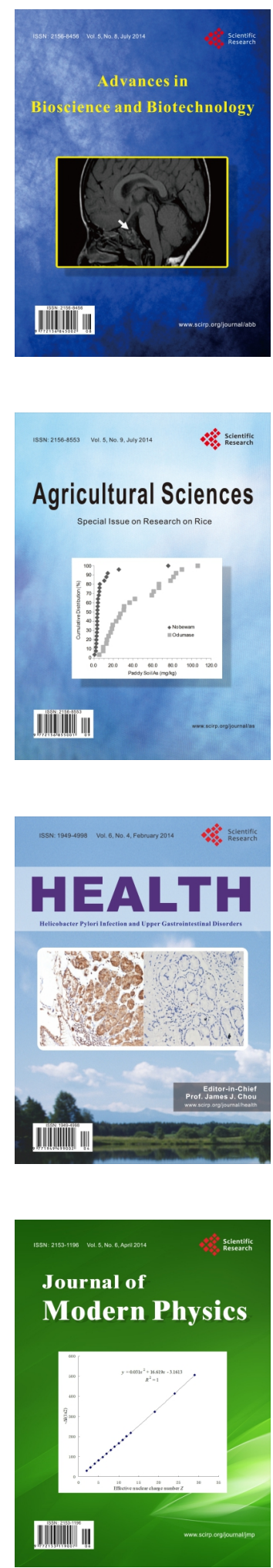
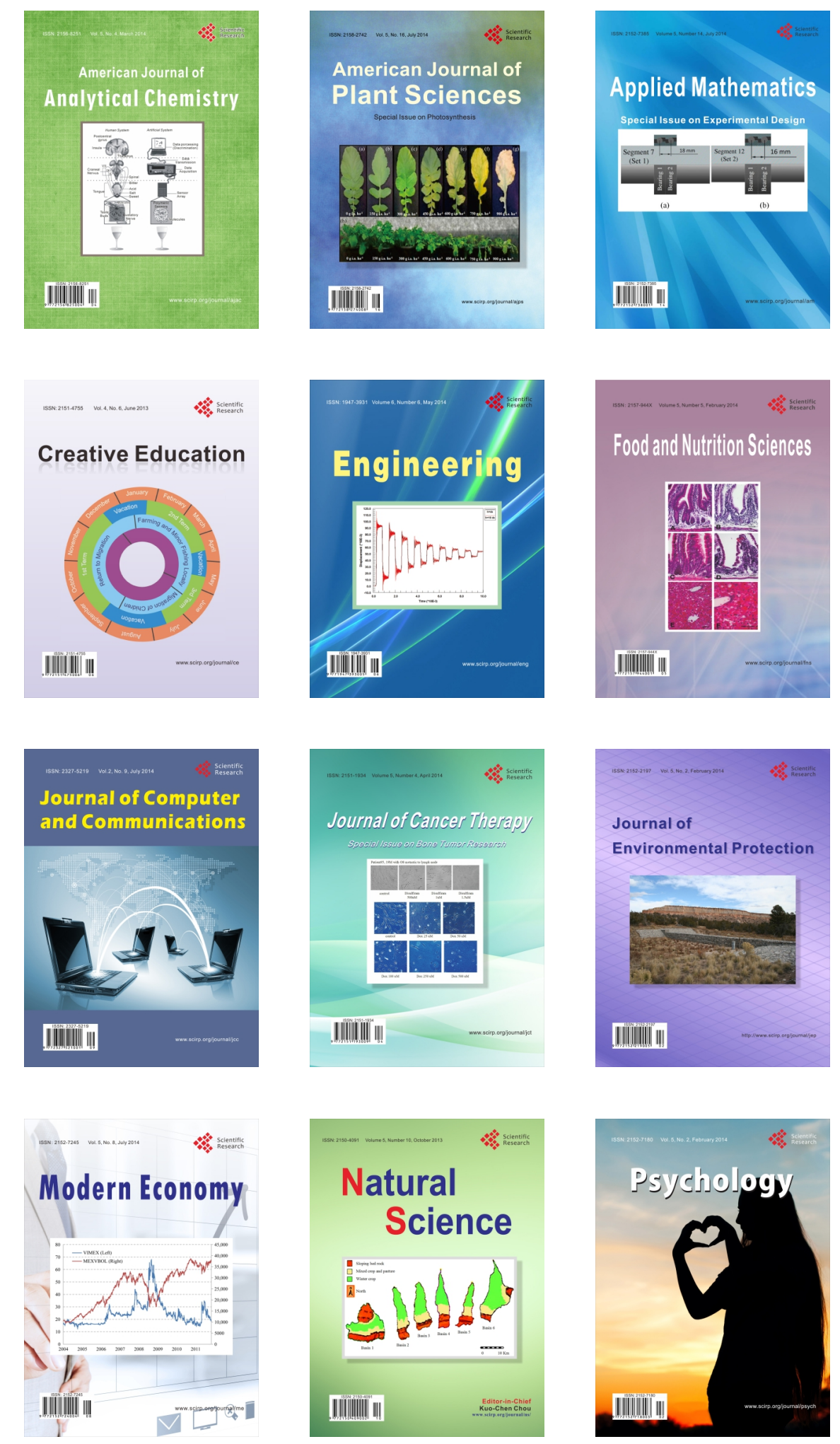